\title{
Chronic Dysphonea in a Child Revealing a Foreign Body: Case Report
}

\section{Lezrag $\mathrm{M}^{*}$, Aboulfadl $\mathrm{M}^{2}$, Halily $S^{1}$, Abada $\mathrm{R}^{1}$, Rouadi $S^{1}$, Roubal $\mathrm{M}^{1}$ and Mahtar $\mathrm{M}^{1}$}

${ }^{1}$ Departement of ENT, 20August Hospital, Ibn Rochd University Hospital, Casablanca, Morocco

${ }^{2}$ Faculty of Medicine and Pharmacy, Casablanca, Morocco

*Corresponding author: Lezrag M, Department of ENT, 20 August Hospital, Ibn Rochd University Hospital, Casablanca, Morocco, E-mail: lezragmokamed13@gmail.com

Citation: Lezrag M, Aboulfadl M, Halily S, Abada R, Rouadi S, et al. (2016) Chronic Dysphonea in a Child Revealing a Foreign Body: Case Report. J Case Rep Stud 4(5): 504. doi: 10.15744/2348-9820.4.504

Received Date: September 01, 2016 Accepted Date: October 28, 2016 Published Date: October 31, 2016

\begin{abstract}
Penetration syndrome is a common reason for consultation in the emergency department.

It is a source of morbidity and mortality, especially in children between 1-3 years old. It is manifested by a sudden onset of choking, coughing and cyanosis while the child is perfectly healthy.

We report the case of a 4 years old boy who suddenly presented dysphonia and dyspnea grade 2 (mMRC scale). He was brought to the emergency room after six weeks of persistent symptoms. The parents did not notice the penetration syndrome. Cervical CT and laryngoscopy showed a foreign body in the glottis and sub glottis. The symptoms disappeared after the removal of the foreign body.

If an airway foreign body is suspected, even in the absence of penetration syndrome or specific symptoms, an endoscopic assessment should be released as late diagnosis and treatment can lead to dramatic consequences.
\end{abstract}

Keywords: Foreign Body; Children; Chronic dysphonea

\section{Introduction}

Foreign bodies of upper aero digestive tract are a common situation in children between 1 and 3 years old, with a peak at two years old and from 6 to 8 years old (little handymen). It is a diagnostic and therapeutic emergency as the main risk is death due to isolation of the foreign body in the sub glottis. However, the absence of penetration syndrome can lead to late diagnosis.

We report the case of a 4 years old boy presenting chronic dysphonia with dyspnea grade 2 (mMRC scale); exploration found a foreign body. Diagnostic facilities, complications and treatment will be discussed with literature data.

\section{Clinical Case}

It is a 4 years old boy with no medical history, in particular; no asthma, acid reflux, penetration syndrome or any similar cases in the family. He suddenly presented a dysphonia with dyspnea grade 2 . The parents did not report penetration syndrome. The dysphonia manifested by a change in tone of the voice which became breathy. The patient was brought to the emergency department after six weeks of persistent symptoms. On the clinical examination, we found bitonal dysphonia, dyspnea grade 2, with general state conservation and no fever.

We discussed the following diagnosis:

- Laryngeal papillomatosis

- Laryngeal hemangioma

- Vocal nodules / polyps

- Epidermal cysts

- Foreign body

- Infection

- Hematoma

Although the beginning of symptoms was acute, but their duration of evolution made us think of tumor pathology in the first, and it is on this point that we chose to start with a cervical CT rather than a laryngoscopy. 
Cervical CT showed the presence at the glottis and sub glottis, to the height of vocal cords, of a linear material, with calcic density, extending between anterior and posterior commissures, reducing the diameter witch remains permeable (Figure 1).

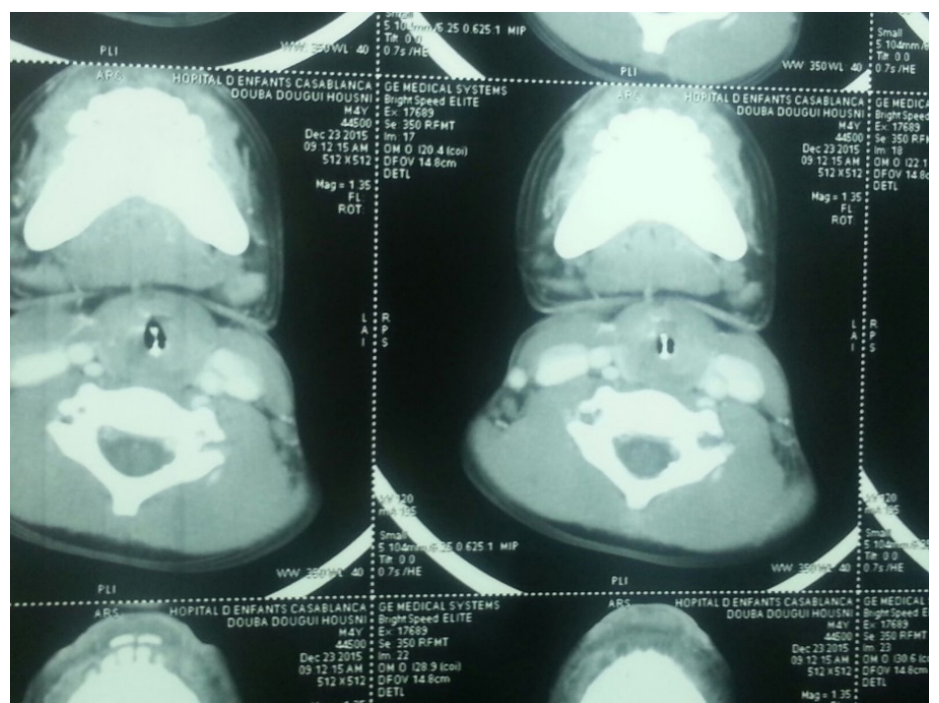

Figure 1: Cervical scan: A glottic and subglottic foreign body giving an aspect of a third vocal cord

Laryngoscopy revealed a foreign body confined in glottis and sub glottis: fish bone (Figure 2). After the removal of the foreign body, we notice an important edema and inflammation. The evolution is marked by significant improvement of the dyspnea and the dysphonia which disappeared completely within 2 weeks. We also administered an antibiotic and a short cure of steroids. Second laryngoscopy performed then was normal.

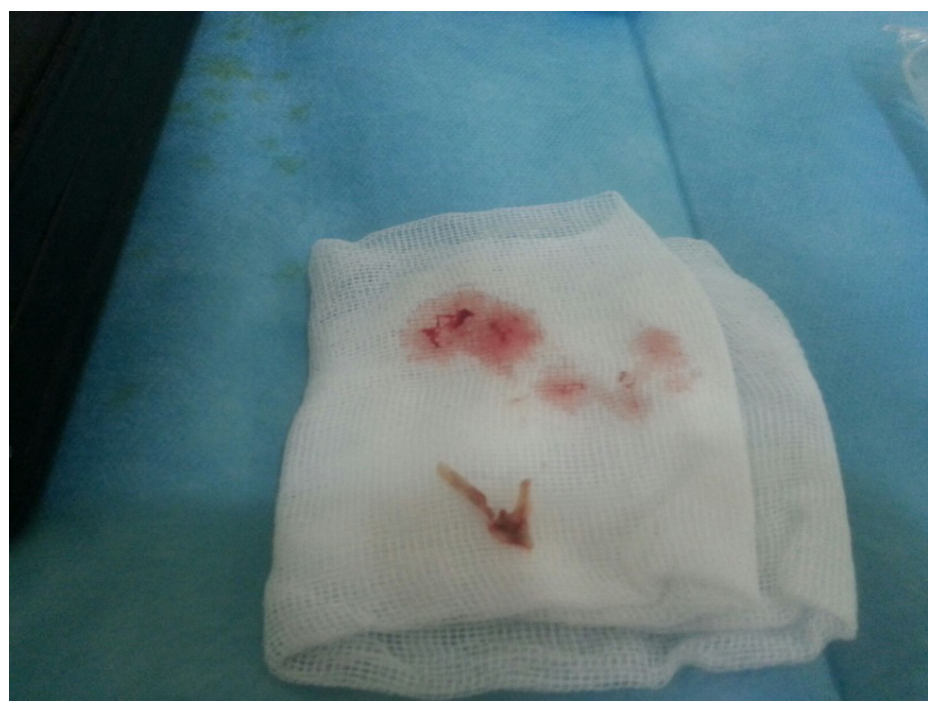

Figure 2: Foreign body: Fish bone fragment

\section{Discussion}

Inhalation risk in children begins at 5 months (acquisition of the gripping) and decreases after 3 years old because mastication is more efficient. The two thirds are boys [1]. The nature of the foreign body is variable with predominance of plant foods $75 \%$, in which $50 \%$ peanuts (this type of foreign body triggers an important inflammatory reaction within a few hours), plastics $15 \%$, metallic $10 \%$, various $5 \%$ (tooth, pencil, paper...). $85 \%$ of foreign bodies are radiolucent [1]. The frequency of foreign bodies inhalation in young children is explained by several reasons [2]. First of all, anatomically, they do not have a complete set of teeth and their larynx is incompletely developed. In fact, it is situated in a higher position than adults and the epiglottis is flaccid which does not allow an efficient protection of the glottis. Secondly, they tend to walk and talk while eating; which increases the risk of choking.

The frequency of inhalation syndrome among children during examination vary between 23 and $83.7 \%$ [3-5]. It occurs as a sudden onset of choking and coughing. It is the pathognomonic penetration syndrome which is often under estimated. Indeed, there might be nobody to witness it. In addition, this syndrome is absent in certain localizations, in particular at the laryngeal edge which can delay treatment. Like in this case, in which CT and laryngoscopy were performed six weeks after the first symptoms. 
Cervical and chest radiography are only released on a stable patient. We look for radiopaque foreign body and some indirect signs such as unilateral pulmonary emphysema or atelectasis [6]. In doubtful clinical forms, chest CT allows a virtual laryngeal- trachealbronchial endoscopy revealing sometimes an intraluminal mass suggestive of the diagnosis [6]. The absence of penetration syndrome and the presence of dysphonia can orientate to other diagnosis such as laryngeal papillomatosis, or subglottic hemangioma [7]. Treatment depend on the clinical state of the patient. In case of asphyxia, Heimlich maneuver should be attempted urgently [8] (Mofsen maneuver on infants). Then emergency transfer to a center with a trained team on upper respiratory tract endoscopy. If the state of the child is stable, it is possible to postpone to a few hours the endoscopy, in order to realize it in the best possible conditions. Meanwhile, antibiotics and steroids can be administered to decrease local edema.

Foreign body inhalation can lead to severe complications: Death (more than 300 per year in the US), pneumothorax, pneumonia, atelectasis, tracheal or bronchial granulomas [9].

\section{Conclusion}

Foreign bodies of upper airway are common in male children. They may go unnoticed and occur with resistant respiratory infections associated with intermittent dyspnea.

They represent an emergency and can be life threatening. Thus, it is important to consider the diagnosis of a foreign body even in the absence of penetration syndrome and perform a CT and an endoscopy of the upper aero digestive tract for diagnostic and therapeutic purposes.

\section{References}

1. Grenoble Medical School [site de la faculté de médecine de grenoble] (2003) Diagnosis of dysphonia (337) Professor Emile REYT - February 2002 (Updated November 2003).

2. Thamboo A, Ludemann JP, Riding KH (2008) Christmas decorations may become aerodigestive foreign bodies. Int J Pediatr Otor-hinolaryngol 3: 57-60.

3. Sissokho B, Conessa C, Petrognani A (1999) Rigid endoscopy, and laryngo-tracheobronchial foreign bodies in children: Reflections about 200 endoscopies performed in the tropics = Rigid bronchoscopy and foreign body removal in children: Lessons from 200 endoscopic procedures in a tropical setting [Endoscopie rigide et corps étrangers laryngo-trachéo-bronchiques chez lenfant: Réflexions à propos de 200 endoscopies réalisées en milieu tropical]. Med Trop (Mars) 59: 61-7.

4. Ouoba K, Diara C, Dao MO, Ouedraogo I, Sanou I, et al. (2002) Laryngo-tracheo-bronchial foreign bodies in children at the University Hospital Center of Ouagadougou (analysis of 96 cases). Med Trop (Mars) 62: 611-4.

5. Tinsa F, Yahyaoui S, Jallouli M, Bousnina D, Slim I, et al. (2010) The larynx and tracheobronchial foreign body in children: predictors of respiratory sequelae [Le corps étranger laryngo-trachéo-bronchique chez l'enfant: facteurs prédictifs des séquelles respiratoires]. Tunisie Medicale 88: 330-4.

6. Tan HK, Brown K, McGill T, Kenna MA, Lund DP, et al. (2000) Airway foreign bodies (FB): a10-year review. Int J Pediatr Otorhinolaryngol 56: 91-9.

7. Haliloglu M, Ciftci AO, Oto A, Gumus B, Tanyel FC, et al. (2003) CT virtual bronchoscopy inthe evaluation of children with suspected foreign body aspiration. Eur J Radiol 48: 188-92.

8. Heimlich HJ (1975) A life-saving maneuver to prevent food chocking. JAMA 234: 398-401.

9. Karakoç F, Karadağ B, Akbenlioğlu C, Ersu R, Yildizeli B, et al. (2002) Foreign body aspiration: what is the outcome? Pediatr Pulmonol 34: 30-6.

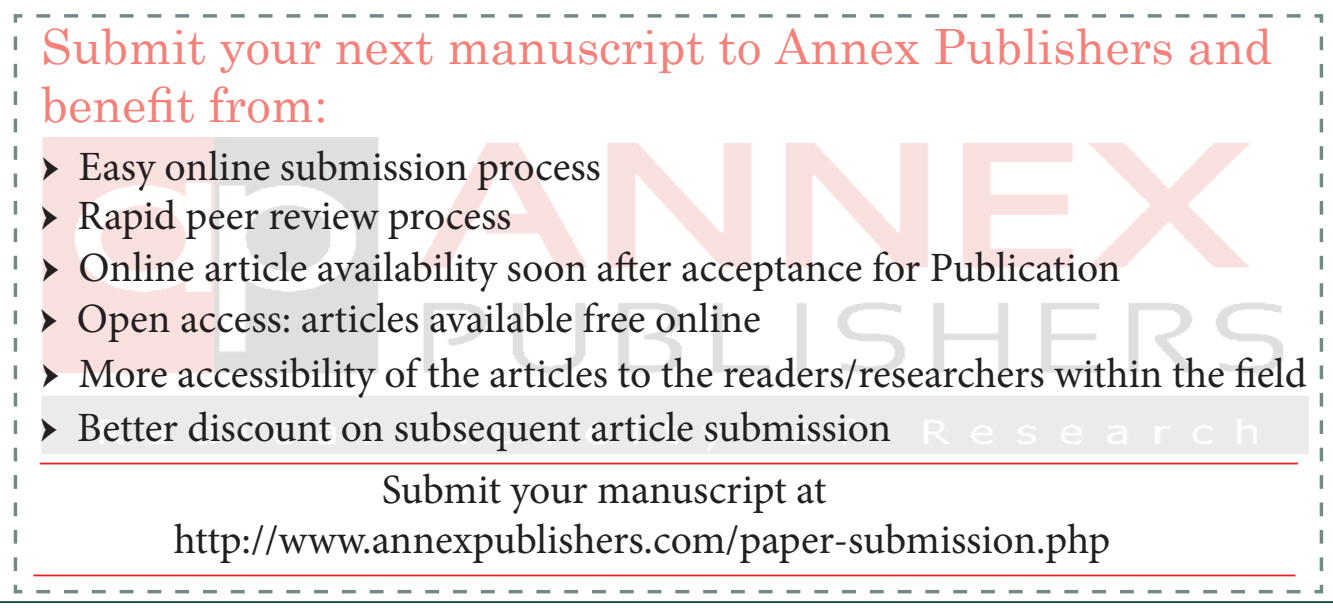

